\title{
CONSUMER BEHAVIOR AFFECTING FACTORS LEADING TO INCREASED COMPETITIVENESS DURING HOLIDAY SEASON
}

Anda Batraga ${ }^{1}$, Dr.oec./prof.; Jelena Salkovska ${ }^{2}$, Dr.oec./ assist.prof.; Aija Legzdina ${ }^{3}$, Mg.Sc./admin.; Ilgvars Rukers ${ }^{4}$ Mg.Sc./admin.; Santa Bormane ${ }^{5} \mathrm{Mg} . \mathrm{Sc} . / \mathrm{admin}$.

\begin{abstract}
A modern consumer nowadays has availability of enormous variety of products and services to choose from when making purchasing decision. This leads to high competition, and companies have to seek new ways and more effective communication measures to successfully influence decision making process of consumers, as well as be creative to forecast consumer behaviour and increase market competitiveness. This is one of the reasons why behavioural research tools are important parts of management decision process. By being able to precisely define expected consumer activities, it is possible to forecast sales amounts, revenue, turnover, and also predict company development potential, especially in periods when sales hit high levels, for example, during holiday season. Consumer behaviour and actions are influenced not only by products, perception of brand values and effectiveness of marketing communication, but also by cultural, social, individual and psychological factors. Analyses of cross-interactions of these aspects allows to reveal which purchasing behavioural model is the most dominating one when buying goods or services.

The aim of this research is to determine the most influencing factors of consumers in Latvia during holiday season, as well as evaluating effectiveness behind various holiday marketing solutions, in order to make argumented marketing decisions to increase competiveness of a company. The research results allow to indicate factors which affect consumption habits, and, based on that, proposals of upgrading marketing solutions for festive periods are revealed, including recommendations for improving marketing communication, appropriate methods of goods and services differentiation, methods of consumer segmentation and other aspects which sharpen competitive edge of a company.
\end{abstract}

Key words: consumer behaviour, marketing communication, marketing tools, competitiveness.

JEL code: M31

\section{Introduction}

A modern consumer nowadays has availability of enormous variety of products and services to choose from when making purchasing decision. This leads to high competition, and companies have to seek new ways and more effective communication measures to successfully influence decision making process of consumers, as well as be creative to forecast consumer behaviour and increase market competitiveness. This is one of the reasons why behavioural research tools are important parts of management decision process. By being able to precisely define expected consumer activities, it is possible to forecast sales amounts, revenue, turnover, and also predict company development potential, especially in periods when sales hit high levels, for example, during holiday season. This means that marketing plays the most vital role for company growth during holiday shopping period. During holiday time consumers get more sensitive and react to different marketing measures in a more specific manner.

Consumer behaviour and actions are influenced not only by products, perception of brand values and effectiveness of marketing communication, but also by cultural, social, individual and psychological factors. Analysis of cross-interactions of these aspects allows to reveal which purchasing behavioural model is the most dominating one when buying goods or services.

The aim of this research is to indicate the mix of right marketing strategy decision aspects in order to increase competiveness of a company, by determining the most influencing factors of consumers in Latvia during holiday season, as well as evaluating effectiveness behind various holiday marketing solutions. In order to reach the aim of the research, four major tasks are 
indicated: 1) analyse aspects and their components which influence and affect consumer behaviour, including decision making process during holiday period; 2) prepare corresponding questionnaire and conduct research among Latvian consumers; 3) analyse and interpret the research results in order to define and identify factors influencing consumer behaviour during holidays, as well as evaluate effectiveness of different holiday marketing measures; 4) develop proposals and recommendations for strategic updates of marketing communication tools and measures which would substantially sustain and increase market competiveness.

Research object - factors influencing consumer behaviour. Subject of research: consumer behaviour affecting factors leading to increased competitiveness during holiday season

During the research, generally accepted quantitative and qualitative research methods of social sciences were used, among them the following ones: referral analyses of literature, content analyses, consumer poll and analyses of statistical results. In the consumer poll, citizens of Latvia were questioned, and their Christmas habits were observed. Christmas was chosen by purpose, since it is the most typical holiday period, thus the most appropriate to analyse holiday consumption specifics.

Based on the conducted research, paper collects and depicts influencing factors of consumers, and purchasing habits during festive period. As a result, it can be concluded, that general consumption has a tendency to increase during holiday season. It is facilitated by individual and psychological factors. It can also be concluded that holiday marketing turns out to be more effective, since return indicators are higher. The research results allow to indicate factors which affect consumption habits, and, based on that, proposals of upgrading marketing solutions for festive periods are revealed, including recommendations for improving marketing communication, appropriate methods of goods and services differentiation, methods of consumer segmentation and other aspects which sharpen competitive edge of a company.

\section{Theoretical background}

Identifying the criteria of consumers' preferences is important to any business when choosing its strategy for boosting the efficiency of competitiveness. It must be admitted that in a competitive economy system some facets of the entrepreneurship depend on knowledge about consumer behaviour. Contemporary authors such as Foxall G.R. and Sigurdsson V. emphasize that the consumer behaviour is foremost related to a human behaviour under natural conditions, taking into account the marketing measures (Foxall G. R., Sigurdsson V., 2013). This statement in fact resonates with an opinion expressed by authors Hatch G., Becker P. and Zyl M. Van, namely that consumer behaviour pertains not only to the very consumer and his decisions, but it closely correlates also to the environmental interaction and varied factors that influence behaviour, such as earlier mentioned marketing measures (Hatch G., Becker P. , Zyl M. Van., 2011b).

It is important to emphasize that during a decision-making about a purchase, a consumer is influenced not only by different external and internal factors, but also is basing his decisions on previous experience. Besides, authors like Kotler, Keller, Joshy and Jha stress that a positive final decision can be disturbed by two factors: negative feedback from other buyers and consumer's motivation to make a purchase and accept others' feedback. Consequently, it is crucial for a consumer to be aware of the importance of such purchase, extent of his readiness to make it and the underlying motivation (Kotler P. , Keller K. L., Koshy A., Jha M., 2012). Authors, such as Efraim 
Turban, David King, Jae Kyu Lee, Ting-Peng Liang and Deborrah C. Turban share an opinion of factor segmentation (Turban, E., King, D., Lee, J.K., Liang, P. T., Turban, C.D., 2016). Consumer behaviour is in fact influenced by factors that can be broken down into two categories: external factors and internal factors, being influential and playing a decisive role in the consumer's decisionmaking process. Sub-sections of the segmentation may vary slightly, but the external factors that belong to general factors having an indirect impact on consumer behaviour actually shape the company's environment that can be good or not so good, as well as general market situation, which also impacts the consumer actions when making a decision about the purchase. Those factors can be anything from political, economic, technical to culture, subculture and social factors (Kotler P. , Armstrong G., 2013).

External factors can be understood better and more precisely than the internal factors, as they reflect individual thoughts, wishes and actions of each individual. They are unique, have their particular features and personal development. This development happens trough learning, human perception, memory that also affects and shapes the individual lifestyle and behavioral model of each person. A set of internal human traits manifests both in person's day to day life, decisionmaking process, lifestyle and when choosing a product or service, making a purchase to change the lifestyle or maintain the existing one (Hawkins D. I., Best R. I., Coney K. A., 2008). Factors affecting the internal environment of a person when making a decision about a purchase:

1) individual factors (personality, lifestyle, age, sex etc.);

2) psychological factors (motivation, perception, learning, beliefs, attitude).

The entire process involving the factors influencing the purchaser is dynamic since it is subject to an ongoing change. Some scientifically proven facts reveal that the consumer behaviour can be considered as taught. The taught discerns between a stimulus and a response where the consumer behaviour is a taught attitude, with the only difference being the way it was taught and what his earlier experience was (Padel S., Foster C., 2005). A set of consumer behaviour and choices made include both very simple and understandable behaviour models and very complicated ones. In order to have an in-depth study of the process, one has to answer particular questions to have a clear understanding of the idea, feeling, experience and action of the consumer. If all listed factors are identified we have come closer to our objective - to comprehend this complicated consumer behaviour having a direct correlation to the company's turnover, market share and competitiveness. Nowadays the market is very saturated; therefore, a great number of companies continuously compete with each other. In fact, the companies fight for the consumer demand and their money. Consumers literally are ones to lead the show and the decision-making is in their hands (Wilkinson N., 2005).

It is obvious that the competition marks contradictions related to overlapping of market participants' goals connected with customers coming from specific groups and target audiences. In a competition struggle, it is usually important to have a situation for achieving a goal where a market share is taken from the rivals under a condition that the total market does not expand (Kramer T., 2000). Meanwhile, other authors emphasize that, if a competition phenomenon is narrowed, all companies suffer due to their overlapping interests and fields of activities. Therefore, the evolution model principle - survival of the fittest - can be applied to the companies. So, if we are to look from such perspective the fundamental issues of business competition must start with 
setting out the strategy. The better companies comprehend and know their consumers and buyers the more competitive they are. So it is crucial to comprehend the factors beneath the consumer behaviour in the most gainful periods of the year, when it is crucial to choose one's strategy that fits the consumers' wishes, needs and behaviour patterns (Vromen J.J., 2013).

\section{Research results and discussion}

A structured data collection by virtue of a survey was conducted to find out what are the factors affecting the consumer behaviour in a holiday season and consequently to evaluate the key factors to focus on in order to boost the marketing communication as well as to ensure a grounded marketing decision-making for the purpose of boosting the efficiency of competitiveness. Due to volume restrictions not all consumer-influencing factors mentioned in the theoretical section were addressed and only the most important ones were discussed. The survey included 406 respondents throughout Latvia. The basic task of the survey was to find out factors affecting the consumer behaviour in one of the most topical holiday seasons - Christmas. Sex distribution of the surveyed respondents: $57.39 \%$ women and $42.61 \%$ men. Youth under 18 years of age were excluded from the survey, assuming that they did not have any personal and constant income for buying Christmas gifts. Age distribution of the surveyed respondents are relatively proportionate; therefore, their replies can be tied in a positive correlation to the age factor.

Respondents were grouped by their income level: below minimum wage, minimum wage, between the minimum and average wage, average wage, above average wage and very high wage. The survey took place in 2017 when the minimum wage in Latvia was 380 EUR and the average wage was 859 EUR before taxes (Minimum wage rates, 2007). The results show that out all respondents $17 \%$ earn below minimum wage, $9 \%$ earn minimum wage, $27 \%$ earn between minimum and average wage, $20 \%$ earn average wage, $25 \%$ earn above average wage and $1 \%$ has very high wage. $1 \%$ selected "other" and marked that they do not have any income. For the purpose of more thorough summary, the respondents were asked to answer the question about their education level. $51 \%$ of respondents had higher education, $25 \%$ had vocational education and $24 \%$ had graduated from the secondary school.

It is equally important to comprehend the consumer behaviour to understand whether the gifts are planned and purchased timely or they are more spontaneous, bought in the last minute relying on a chance to get something appropriate. It is crucial to know the periods for which the companies should have to intensify their marketing communication to boost their product or service sales. It can be concluded that the majority or $67.50 \%$ of respondents bought gifts at the last minute (1-2 weeks before the holidays), yet $24.8 \%$ of respondents told that they bought gifts timely. Even though the majority of respondents buy gifts at the last minute, the companies during holiday season have to think timely about their marketing communication and must communicate intensively. It is necessary because a consumer, when deciding on a gift at the last minute, would intuitively remember also the advertised offers.

The economic factor. This is one of the most important factors affecting the consumer behaviour and decision-making therefore respondents were asked about the amount of money spent for gifts. The major part or $43.60 \%$ responded that they spend 51-150 EUR, and it helps us conclude that people either do not buy expensive gifts or their wage level is not that high to afford them. $29.06 \%$ of respondents replied to this question saying that they spend 1-50 EUR and 
$3.69 \%$ of respondents told they do not buy gifts and a reason for that could be traditions or family habits, such as not to give presents to each other. $19.95 \%$ out of all respondents indicated that during Christmas season they buy gifts worth 151-300 EUR and 3.20\% told that the total amount spent for gifts is 301-500 EUR. These respondents mainly have high correlation to the income level, and the majority of them are persons with average and averagely high income, and they perceive giving gifts as important act and wish to give joy with presents to their family and friends. $0.49 \%$ of respondents told that they spend over 500 EUR for gifts. As can be concluded, this group of people have high income and they are respondents who find recipients' wishes to be crucial factor and do not pay attention to the product price (Figure 1).

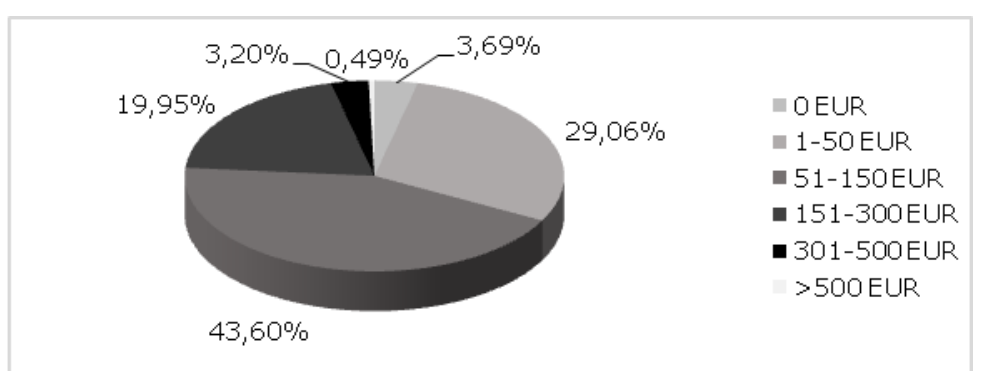

Source: author's chart based on the survey conducted in October-December 2017

\section{Fig. 1 How much money respondents spend on Christmas gifts}

The political factor. Often an affiliation with some group or even a patriotic stance is very important when making a decision about a purchase. Figure 4 shows the replies of respondents and subjective assessment of how much their gift buying process is influenced by the local producers' offer. $30.79 \%$ replied that the local producers' offer rather influences the gift buying process, $28.33 \%$ were neutral regarding this factor, $16.50 \%$ replied that the local offer affects their gift purchases, $16.01 \%$ of respondents said that this factor has no impact and $8.37 \%$ of respondents told that it rather does not have any impact. From given data we can conclude that the respondents' values and attitude towards the local producer vary (Figure 2 ). It is clear that the consumers who pay attention to the country of origin of products are more liable to make a decision in favour of the locally produced goods. Therefore, the companies targeting this criterion can direct their marketing communication with a special emphasis on said criterion, highlighting it as a unique sales argument.

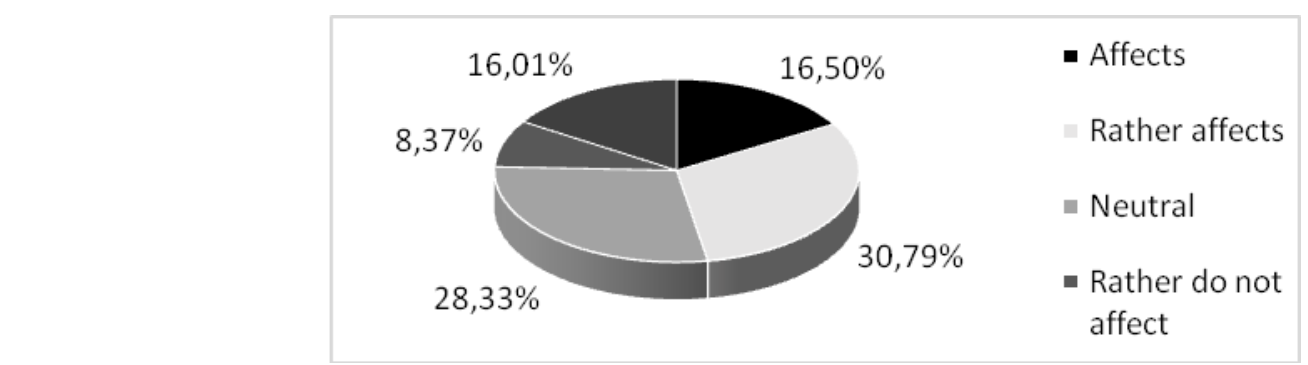

Source: author's chart based on the survey conducted in October-December 2017

Fig. 2. Local brand/manufacturer as an influencing factor on purchasing decision

In order to find out where a potential consumer should be addressed at best, one must know where the gifts are commonly purchased. More than a half of respondents or $57.65 \%$ told they buy gifts in shops (traditional points of sale), $23.09 \%$ buy gifts at Christmas fairs and only $15.14 \%$ buy them in internet. $4.13 \%$ chose "Other" (do not purchase, habits vary from year to 
year or make DIY gifts). We can therefore conclude that the largest part of potential consumers can be met in the traditional points of sale where marketing activities would be most gainful as they reached and addressed the maximum number of buyers. Another essential factor of these points of sale are physical buying allowing to view the product in life before purchasing it. The producers selling only via internet should think more of addressing a consumer through contemporary communication channels in internet, such as social networks, or to consider a possibility to participate in Christmas fairs to reach out to more consumers (Figure 3).

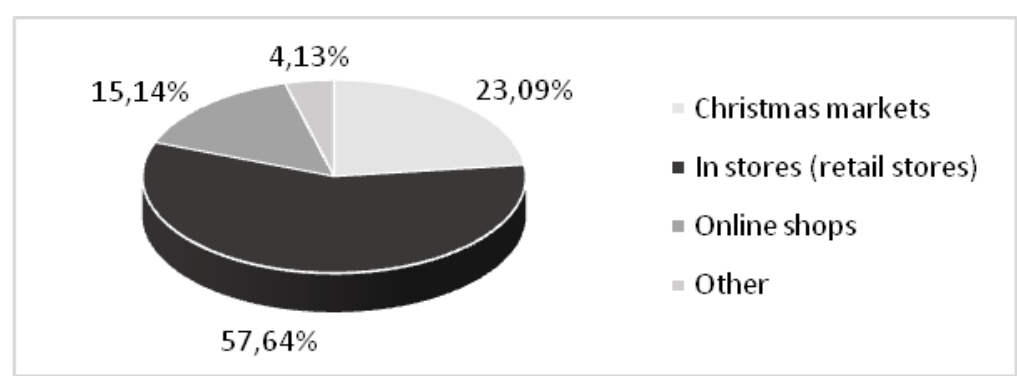

Source: author's chart based on the survey conducted in October-December 2017

Fig. 3. Where respondents purchase their Christmas gifts

The environmental factor. Today increasingly more attention is paid to the environmental protection, prevention of pollution etc. Therefore, Figure 5 shows an extent to which people consider environmental aspects when buying their presents. Results show that the majority or $27.83 \%$ of respondents treats this factor neutrally. Approximately $1 / 4$ or $25.86 \%$ of respondents do not bother if their product and/or its packaging is environmentally friendly. A slightly less number of respondents, i.e. $22.17 \%$ told that this factor rather does no impact them. Only about $1 / 5$ or $20.44 \%$ of respondents are rather influenced by the fact that the product and/or package is environmentally friendly. The minority or $3.69 \%$ are respondents that care for the environmental impact of the product and packaging (Figure 4). It leads to a conclusion that the major part of Latvian residents, when buying Christmas gifts, do not consider whether the product and/or packaging are environmentally friendly (only less than $1 / 4$ of population pays attention to said fact). Therefore, the entrepreneurs should not aim at environmentally friendly packaging due to their marketing activities; it would rather be necessary for a company to position itself as socially responsible, but as one can see in the depicted results, most likely it will not influence consumer behaviour in a decision-making process.

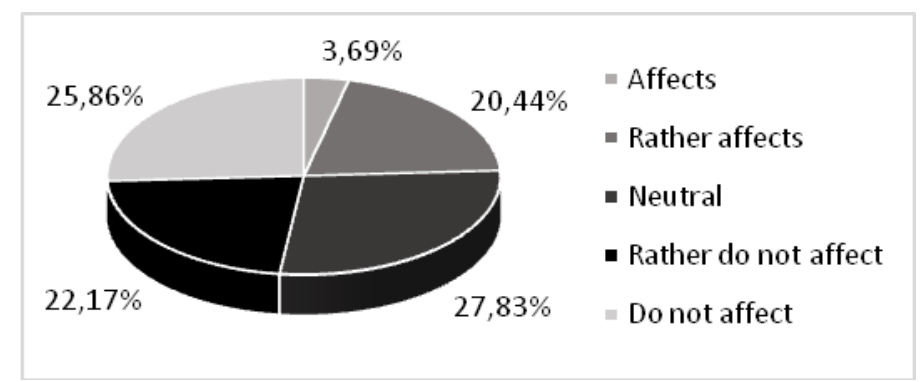

Source: author's chart based on the survey conducted in October-December 2017

Fig. 4. Nature friendly goods/ packaging as an influencing factor on purchasing decision

The study reflects that the most efficient communication channels to address a consumer in the gift shopping period is internet $22.56 \%$, friends and acquaintances $21.04 \%$, showing that "verbal feedback" is still one of the most efficient and reliable sources. Also outdoor advertising is a ${ }^{1}$ Corresponding author. Tel.: + 371 29224223; E-mail address: anda.batraga@lu.Iv ${ }^{2}$ Corresponding author. Tel.: +371 29615933; E-mail address: jelena.salkovska@lu.lv

${ }^{3}$ Corresponding author. Tel.: +371 29127075; E-mail address: aija.legzdina1@gmail.com

${ }^{4}$ Corresponding author. Tel.: +371 25448199; E-mail address: ilgvars.rukers@gmail.com ${ }^{5}$ Corresponding author. Tel.: +371 26582423; E-mail address:santa.bormane@gmail.com 
perspective and efficient information channel, marked by $20.15 \%$ of respondents in their answers. Interestingly, TV ads have been marked merely by $10.90 \%$ of respondents. Authors of the paper explain that during this period the advertising share is very intense and also the number of offered ads is very large, advertising times are very saturated with different advertisements, therefore consumers find it difficult to perceive the communication messages. They are followed by advertising in magazines with $9.76 \%$, newspapers with $5.58 \%$ and cinema with $0.51 \% .7 .48 \%$ of respondents marked Other (do not buy, know a particular item in advance, individual approach to each receiver, think individually or rely on the mood). From the obtained data one can conclude that the companies should focus more on communication in internet and outdoor advertising as the main influence on the consumer behaviour in favour of gift shopping during the holiday season (Figure 5).

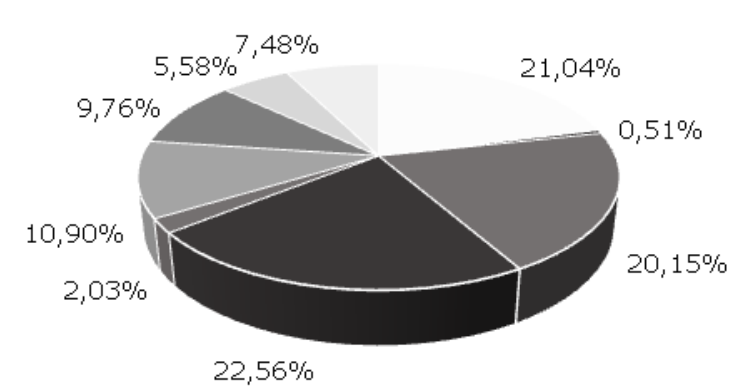

$$
\begin{aligned}
& \text { Friends } \\
& \text { - Cinema } \\
& \text { - Environment } \\
& \text { - Internet } \\
& \text { - Radio } \\
& \text { - Television }
\end{aligned}
$$

\section{Source: author's chart based on the survey conducted in October-December 2017}

\section{Fig. 5. Most effective media channels for reaching Christmas gift buyers}

In the concluding part of the research, authors looked at the individual value system of a person and the way it can change the habits of gift purchases; respondents were asked about their value system. Each factor in the question had to be rated by its importance ( 5 - relevant and 1 irrelevant). By analysing the obtained data, each factor with the attributed relevance assessment was translated into percentage where $100 \%$ express relevance and $0 \%-$ irrelevance. The obtained results reveal that the most important factor is family with $96.2 \%$, and it correlates with the fact that the majority of respondents celebrate Christmas with their families. The second most relevant factor is health, receiving $94.38 \%$, and safety takes the third place with $84.63 \%$. The most relevant factors are related to intangible values (Figure 6).

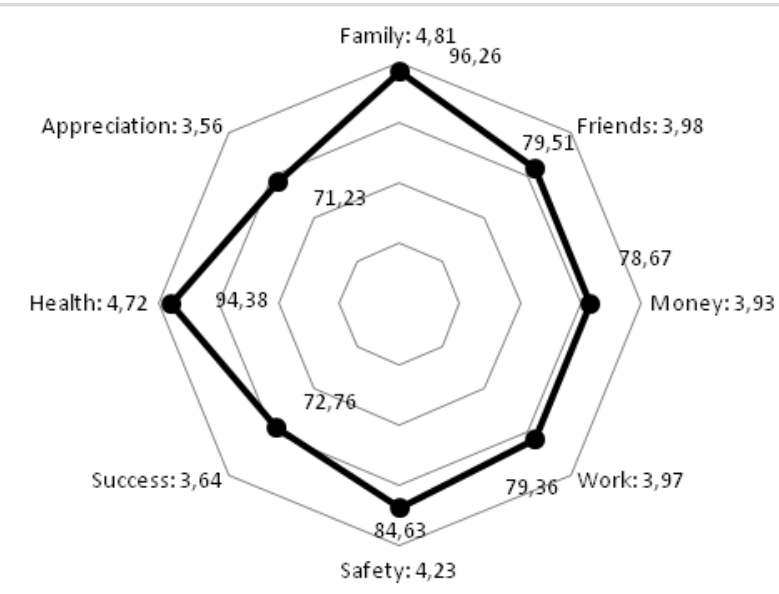

Source: author's chart based on the survey conducted in October-December 2017

Fig. 6. Value system of respondents 
Results of Figure 7 reflect values that the consumers hold dear and hence they reflect also directions where the companies can communicate and build their strategy. Since $96.2 \%$ of the respondents placed family as the most important value, it is one of the factors to be taken into account when offering products and services during the holiday season.

\section{Conclusions, proposals, recommendations}

1) In a competitive economy system, some facets of the entrepreneurship depend mainly on knowledge about consumer behaviour.

2) Notwithstanding the fact that the majority of the respondents bough gifts at the last minute, the companies must think and plan marketing communication timely during the holiday season in order to boost their competitiveness, because it takes time to create a qualitative message and to deliver it to a consumer.

3) The income level of the respondents closely correlates to the consumed amount of money for gifts - the higher the income, the larger the amount spent for gifts.

4) Consumers who pay attention to the country of origin of products are more liable to make a decision in favour of the locally produced goods. Therefore, companies targeting this criterion can direct their marketing communication with a special emphasis on said criterion, highlighting it as a unique sales argument.

5) The most efficient communication channels to address a consumer in gift shopping period is internet $(22,56 \%)$ as well as friends and acquaintances $(21,04 \%)$. The companies should focus more on communication in internet and outdoor advertising as the main influence on consumer behaviour in favour of gift shopping during the holiday season.

6) Values that are relevant for consumers reflect also directions where the companies can communicate and build their strategy to improve the efficiency of competitiveness. Since $96.2 \%$ of respondents selected family as the most important value, it is one of the factors to be taken into account when offering products and services during the holiday season.

7) As the consumers are ready to spend more during the holiday seasons, they have the biggest potential for companies' profit and they should take an advantage of them to increase their turnover.

8) Companies should think about locations where to reach out for potential customers; one of the most efficient communication channels to use is traditional points of sale, paying a special attention to the on-site measures at stores where gifts for this period are most frequently purchased thus reaching the maximum mass of potential buyers.

9) When elaborating the research further, it would be useful to look at the most characteristic gift categories for each age group; it would help to comprehend the consumer behaviour and trends to a deeper level and the companies could understand suitability of their product or goods for each age group and accordingly make their communication range more efficient.

\section{Bibliography}

1. Foxall, G. R., \& Sigurdsson, V. (2013). Introduction to the Special Issue: Consumer Behavior Analysis: Behavioral Economics Meets the Marketplace. The Psychological Record, 63(2), pp. 231-238.

2. Hatch, G., Becker, P. , \& Zyl, M. Van. (2011b). The Dynamic African Consumer Market: Exploring Growth Opportunities in Sub-Saharan Africa. Accenture. p. 44.

3. Hawkins, D.I., Best, R. I., Coney, K. A. (2008). Consumer Behavior. United States: John Wiley \& Sons, p. 576. 
4. Kotler, P. , Armstrong, G. Principles of Marketing. (2013). Thirteenth Edition. United Kingdom: Pearson Education, pp. 191-193.

5. Kotler, P. , Keller, K. L., Koshy, A., \& Jha, M. (2012). Marketing Management Thirteenth Edition. New Delhi: Pearson Education, p. 816.

6. Kramer, T. (2000), Podstawy marketingu. Warszawa: PWE, p. 39.

7. Minimalas algas likmes (Minimum wage rates) (2017). Retrieved: https://www.vid.Iv/minim257l257alga.html. Access: 12.12.2017.

8. Padel, S., Foster, C. (2005). Exploring the Gap between Attitudes and Behavior: Understanding why consumers buy or do not buy organic food. British Food Journal, p. 606.

9. Turban, E., King, D., Lee, J.K., Liang, P. T., Turban, C.D. (2016). Electronic Commerce. A managerial and social networks perspective. Eight edition. New York: Springer. p. 791.

10. Vromen, J.J. (2013). Competition as an Evolutionary Process: Mark Blaug and evolutionary economics. Erasmus Journal for Philosophy and Economics, 6 (3), pp. 104-132.

11. Wilkinson, N. (2005). Managerial Economics. A Problem-Solving Approach. Cambridge University, p. 556. 